\title{
Microlayered Composite Materials on Basis of Copper, Refractory, Rare-Earth Metals, and Carbon for Electrical Contacts and Electrodes
}

\author{
Victor Volodymyrovych Bukhanovsky¹, Mykola Petrovych Rudnytsky', Ilija Mamuzich ${ }^{2}$ \\ ${ }^{1}$ Department of Computational and Experimental Analysis for Structural Strength, Pisarenko Institute for \\ Problems of Strength, National Academy of Sciences of Ukraine, Kyiv, Ukraine \\ ${ }^{2}$ Faculty of Metallurgy, University of Zagreb, Zagreb, Croatia \\ Email: nadiynist@ipp.kiev.ua, llija.Mamuzic@public.carnet.hr
}

Received 3 January 2014; revised 3 February 2014; accepted 15 February 2014

Copyright $@ 2014$ by authors and Scientific Research Publishing Inc.

This work is licensed under the Creative Commons Attribution International License (CC BY). http://creativecommons.org/licenses/by/4.0/

(c) (1) Open Access

\begin{abstract}
A technology for obtaining microlayered composite materials of $\mathrm{Cu}-\mathrm{Zr}-\mathrm{Y}-\mathrm{Mo}, \mathrm{Cu}-\mathrm{Zr}-\mathrm{Y}-\mathrm{Cr}$, $\mathrm{Cu}-\mathrm{Zr}$ $\mathrm{Y}-\mathrm{W}$ and $\mathrm{Cu}-\mathrm{Zr}-\mathrm{Y}-\mathrm{C}$ systems by means of high-speed electron-beam evaporation-condensation, structure, electrical, and mechanical properties at ambient and elevated temperatures is developed.
\end{abstract}

\section{Keywords}

Microlayered Condensed Composites, Electron-Beam Technology, Material Structure, Electroconductivity, Mechanical Characteristics

\section{Introduction}

Composite materials (CMs) based on copper, refractory metals (tungsten, molybdenum and chromium) and carbon, which exhibit a number of unique physical, mechanical, chemical, technological and performance characteristics, were developed in the second half of the last century. Due to their specific structure and chemical composition they combine high heat-resistance, hardness, erosion and electric-erosion resistance, resistance against micro-welding typical of refractory metals, and high thermal and electrical conductivity, low contact resistance typical of copper and carbon. In addition, these materials are easy to process. Up to now, CMs of this type had been obtained by the methods of powder metallurgy. One of traditional powder metallurgy manufacturing pro- 
cesses is to press the refractory metals, sinter the pressed porous compact at a high temperature, and infiltrate with copper. Other traditional manufacturing process is hot-pressing of powder mix of refractory metals or carbon and copper. All this is done under very closely controlled conditions. Despite many years of experience with these materials, studies of their properties proceed within the system concerned in connection with the improved technical possibilities to control the material composition, dispersion and distribution of the refractory component in the product volume [1]-[7].

CMs based on copper, refractory metals and carbon are used as electrical, structural and special purpose materials for the production of parts and structural elements to be in service under conditions of high temperatures, erosive and electroerosive wear, and other extreme operational factors. The composites of the $\mathrm{Cu}-\mathrm{W}, \mathrm{Cu}-\mathrm{Mo}$, $\mathrm{Cu}-\mathrm{Cr}$ and $\mathrm{Cu}-\mathrm{C}$ systems concerned found the widest application in electrical engineering as materials for contact parts of high-current switchgears, current-collecting devices, and electrodes for contact welding. The electrical and thermal conductivity of refractory metals, which is lower as compared to that of pure copper, calls for the creation of new technologies for producing combined products. These composites can be used in such products only as coatings for contact parts of electrical switchgears that change their functional properties appreciably. In using this technology, difficulties occur due to the need in checking the quality of the boundary between the copper body and the composite coating. In a number of cases, these difficulties can be avoided, and a separate production of coatings and contact parts can be discontinued due to the technology that allows producing layered gradient composites and coatings based on them directly on the working surface of contact parts.

The production of such materials became possible after the creation of electron-beam facilities for high-speed evaporation of composite components from separate water-cooled crucibles with a subsequent layer-by-layer condensation of the regulated vapor flows on the revolving metallic substrate [8]-[17]. The apparent advantages of the electron-beam technology, which allowed obtaining the new-generation composite materials for electrical contacts, include:

- the possibility to mix at the atomic and molecular levels the vapor flows of substances that do not dissolve well in each other, and obtain composite materials and coatings (facing layers) with the assigned structure, chemical composition, physical, mechanical and performance characteristics, which cannot be yielded by other methods;

- simplicity and efficiency as compared to the methods of powder metallurgy, as the material is formed over one technological cycle;

- the possibility to create gradient structures by varying the deposition rate of the components being evaporated in the course of the technological process;

- the possibility to obtain layered composite materials, which is practically impossible to achieve using traditional methods;

- ecological purity, as this technology eliminates all atmospheric emissions.

\section{Material, Treatment, and Testing}

The objects for the investigation were the microlayered CMs of the Cu-Zr-Y-Mo, Cu-Zr-Y-Cr, Cu-Zr-Y-W and $\mathrm{Cu}-\mathrm{Zr}-\mathrm{Y}-\mathrm{C}$ systems for electrical contacts, which were formed by the electron-beam technology at Gekont (Eltechmash) Science \& Technology Company, Ukraine [8]-[10]. The electrical engineering materials condensed from the vapor phase were obtained on the L-5 electron-beam facility designed at the Paton Welding Institute of the National Academy of Sciences of Ukraine and upgraded at Gekont Science \& Technology Company to suit our task. The scheme and surface appearance of the facility is given in Figure 1 and Figure 2.

The facility represents technological work chamber 1 . The side wall of the work chamber has gun chamber 2 attached to it, which contains electron-beam heaters 3, 4, 5 and 6. The vacuum system, which comprises two fore pumps, two booster pumps and two high-vacuum units, serves to provide dynamic vacuum in the facility chambers for evaporation and condensation of the initial materials.

On the upper flange of the work chamber 1 there is mechanism 15 that rotates substrate 14 . Substrate made in the form of a steel disk $1000 \mathrm{~mm}$ in diameter and $20 \mathrm{~mm}$ in width. The substrate surface which was presented to the crucibles and on which the condensation occurred was polished to achieve N8-N9 surface finishes. The design of rotation mechanism allows it to be operated for a long time without destroying vacuum at a temperature of $870 \pm 50 \mathrm{~K}$.

The substrate fixed to rotation rod 7 was heated to the assigned temperature by $40 \mathrm{~kW}$ electron-beam heaters 


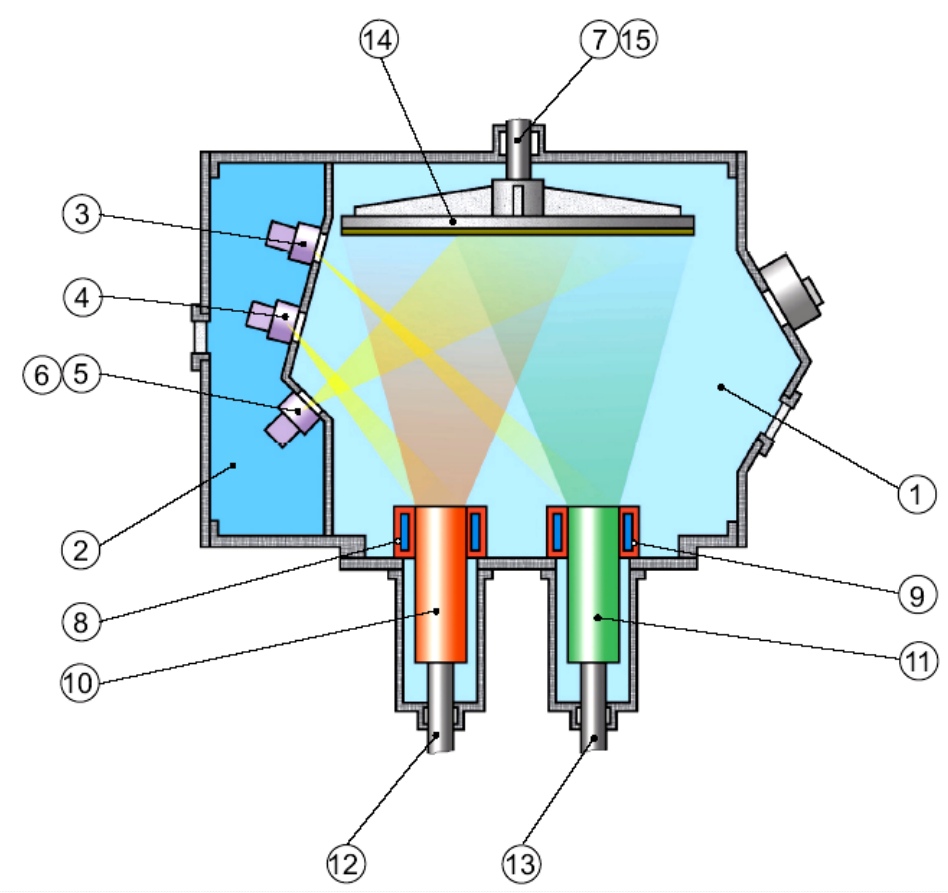

Figure 1. Scheme of the electron-beam facility. Designations: 1: work chamber; 2: gun chamber; 3-6: electron-beam heaters; 7: substrate rotation rod; 8: crucible for evaporation of copper; 9: crucible for evaporation of refractory metals or carbon; 10, 11: ingots of copper and refractory metals or carbon, respectively; 12, 13: mechanisms for supplying ingots in the vapor flow zone; 14: steel substrate for condensation of copper and refractory metals or carbon vapor flows; 15: substrate rotation mechanism.

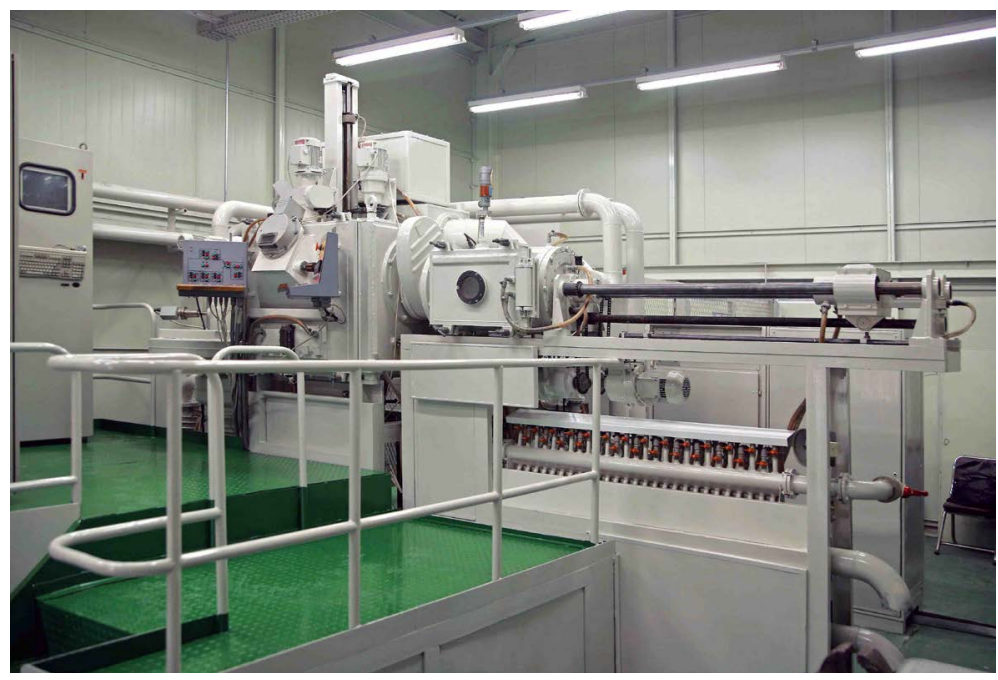

Figure 2. Surface appearance of industrial electron-beam facility L-5.

5 and 6 . The initial materials were heated to evaporation by $100 \mathrm{~kW}$ electron-beam heaters 3 and 4 . All heaters have independent cathode-glow and electron-beam controls.

The evaporation unit has two water-cooled copper crucibles 8, 9 of diameter 100 and $70 \mathrm{~mm}$ for evaporation of copper ingot 10 of diameter $98.5 \pm 0.1 \mathrm{~mm}$ and length up to $500 \mathrm{~mm}$ and refractory metals (or carbon) ingot 11 of diameter $68.5 \pm 0.1 \mathrm{~mm}$ and length $300-320 \mathrm{~mm}$ long to be evaporated, and mechanisms 12, 13 that allow the ingots to be put in the evaporation zone. 
In the present investigation, we obtained the CMs based on copper, refractory and rare-earth metals by means of copper, zirconium, yttrium and tungsten (molybdenum, chromium or carbon) evaporation from separate crucibles followed by their precipitation on a rotated steel substrate coated with a separating layer of calcium fluoride. The initial materials were M0 grade copper ingots with $100 \mathrm{~mm}$ diameter, MChVP grade molybdenum (Kh99 grade chromium, VA grade tungsten or MPG-7 carbon) ingots with $70 \mathrm{~mm}$ diameter as well as toughpitch zirconium and yttrium batches.

The copper matrix was alloyed with zirconium and yttrium as follows. Two batches of these components, 135 g each, were put on the surface of the copper ingot. On reaching a vacuum to $(1.3-4.0) \times 10^{-3} \mathrm{~Pa}$ in the work chamber, we performed the electron-beam heating of the substrate, on which vapors were to be condensed, up to the temperature $950 \pm 15 \mathrm{~K}$. Simultaneously, we heated the surface of the copper ingot, making the constituents (zirconium, yttrium, copper) lying on it melt at a current of 1.15 - 1.3 A. The melt pool became homogeneous after 15 - 20 minutes of heating. At the production stage the evaporation of copper ingots was performed at a beam current of 2.6 - 2.8 A under acceleration voltage $20 \mathrm{kV}$. The total content of zirconium, yttrium, and their oxides in composites was no more than $0.8 \mathrm{wt} . \%$ in all cases.

Tungsten (molybdenum, chromium or carbon) was evaporated from the other crucible. Considering very high melting temperature of carbon and the difficulty of its transformation into a vaporous state the original electron-beam technology of carbon evaporation through molten tungsten mediator was designed by the Gekont Science \& Technology Company. By varying the beam current in the range from 1.7 to $3.8 \mathrm{~A}$ under the direct acceleration voltage $20 \mathrm{kV}$, one can readily regulate the evaporation rate of refractory components and its concentration in the composite in wide ranges. Optimal content of refractory component in composite, which yields the most beneficial combination of their electric, mechanical, chemical, and operating characteristics, depends on material functionality and is determined experimentally. Generally for tungsten it lies between 5 - 25 mas.\%, for molybdenum between 2.5 - 12.0 mas.\%, for chromium between 30 - 40 mas.\%, and for carbon between 1.2 to 7.5 vol.\%.

By maintaining the substrate temperature in the range from 935 to $965 \mathrm{~K}$, we prevented the re-evaporation of copper from the surface of the condensed material. The resulting condensed materials was a $\sim 3 \cdots 5 \mathrm{~mm}$ thick plate.

At the end of the technological process condensed composite material was separated from the substrate and annealed in the vacuum furnace at $1170 \mathrm{~K}$ for $3 \mathrm{~h}$ in order to relieve internal stresses, make the structure stable and enhance the material ductility.

At present time commercial and experimental-industrial condensed CMs of the Cu-Zr-Y-Mo, Cu-Zr-Y-Cr, $\mathrm{Cu}-\mathrm{Zr}-\mathrm{Y}-\mathrm{W}$, and $\mathrm{Cu}-\mathrm{Zr}-\mathrm{Y}-\mathrm{C}$ systems for electrical contacts and electrodes are manufacturing in Ukraine by the Gekont Science \& Technology Company the in the form of sheets by $3 \cdots 5 \mathrm{~mm}$ thick. Generally, these sheet materials are used as operating floors of copper electrical contacts and electrodes attached to them by brazing.

In this study, we used the research techniques that include the macro-and microstructure analysis using optical and scanning electron microscopy, electrical resistance methods, mechanical tensile tests at room and high temperatures, measurement of hot hardness.

The structure, chemical composition, electrophysical, tribotechnical and mechanical properties of the condensed materials were investigated on specimens cut from the plates. Specimen dimensions were set in accordance with the requirements for specimens to be used for studying the material structure, electrical conductivity, microhardness, tribotechnical and mechanical characteristics during tensile tests. The content of tungsten, molybdenum, chromium, carbon and copper in composites was determined by the mortar method (volumetric analysis).

The structure of the composite materials was investigated by optical and scanning electron microscopy using the "Neophot-2" optical microscope and the "Superprobe 733" raster electron microscope manufactured by "Jeol”. Specimens for metallographic analysis were prepared using chemical etching in a $40 \%$ hydrochloric acid solution and ion etching in a glow discharge. We studied the specimen surface and cross section perpendicular to the substrate, on which vapors were to be condensed.

The mechanical characteristics were determined at ambient temperature (in air) and in the range 370 - $1070 \mathrm{~K}$ (at a pressure no more than $0.7 \mathrm{mPa}$ ) from the results of mechanical tensile tests of standard flat fivefold proportional specimens with a gauge length of $15 \mathrm{~mm}$, width of $3 \mathrm{~mm}$ and thickness of $1.2-2.0 \mathrm{~mm}$ using a 1246-R unit [18] according to ISO 6892 [19] and ISO 783 [20], respectively. The specimens were cut from $1.2-2.0 \mathrm{~mm}$ thick composite materials. We tested from 3 to 5 specimens at each temperature. The deformation rate was 2 
$\mathrm{mm} / \mathrm{min}$, which corresponded to a relative strain rate of $\sim 2.2 \times 10^{-3} \mathrm{~s}^{-1}$. During the tests deformation diagrams were recorded to determine the proof strength $R_{\mathrm{p} 0,2}$, the ultimate strength $R_{\mathrm{m}}$, the percentage elongation after fracture $A$, and the percentage reduction of cross-sectional area $Z$.

Hardness of the CMs was measured in the temperature range from 20 to $1070 \mathrm{~K}$ by Vickers indentation in the plane parallel to the surface of condensation. The pyramidal point was made of a synthetic corundum single crystal. Indentation loads were $10 \mathrm{~N}$. The tests were carried out at a pressure no more than $0.7 \mathrm{mPa}$ on a UVT-2 unit [21] [22] according to the DSTU 2434-94 [23].

\section{Results and Discussion}

Numerous properties requirements which a material for electrical contacts should meet are highly inconsistent and are mainly dictated by their operating conditions. To meet these requirements, the contacts should be made from a material possessing a certain complex of physical, structural, mechanical, and electrical contact properties. In particular, these properties include high electrical and thermal conductivity, melting temperature, high critical current strengths and voltages, strength characteristics, low contact resistance, high electrical erosion and corrosion resistance, volatility of its oxides, ease of processing, relatively low prime cost and environmental compatibility. At present, none of the known electrical contact materials possess the full set of the above properties.

By applying the layer-by-layer condensation of low-alloy copper and refractory metals (tungsten, molybdenum or chromium) or carbon and moving the substrate out of the zone of vapor flow while it is rotating, it is possible to perform tempering from vapor and obtain materials with the structural elements typical of nanomaterials. Investigated composites are characterized by a specific microlayer structure with alternating layers of Cu-Zr-Y low alloy and refractory metals from 0.1 to $0.4 \mu \mathrm{m}$ thick (Figure 3(a) and Figure 3(b)). The grain size of copper in the composite is $0.1-0.3 \mu \mathrm{m}$ and that of tungsten (molybdenum or chromium) from $0.01-0.02 \mu \mathrm{m}$. Composites $\mathrm{Cu}-\mathrm{Zr}-\mathrm{Y}-\mathrm{C}$ has layered structure with cuprum grain size $0.1-0.3 \mu \mathrm{m}$ and disperse particles of carbon which mean size does not exceed $200 \AA$ (Figure 3(c) and Figure 3(d)).

Commercial composite materials by Cu-Zr-Y-Mo system for electrical contacts are produced serially by the Gekont Science \& Technology Company in three modifications: MDK-1, MDK-2 and MDK-3 with the molybdenum content of 2.5 - 5.0, $5.1-8.0$, and 8.1 - 12.0 wt.\%, respectively. Standard values of physical and mechanical characteristics of MDK grade composite materials and rated currents for contacts produced on their basis are given in Table 1.

In operation, the materials of contacting pairs in high-current switchgears are subjected not only to intensive corrosion and electrical erosion but also to mechanical loads at elevated temperatures. Therefore, studies on their mechanical properties over operating temperature ranges are of definite scientific and practical interest. Table 2 lists the mechanical characteristics of the most promising composite material MDK-3 in the temperature range from 290 to $1070 \mathrm{~K}$. This composite material exhibit a unique complex of mechanical characteristics combining high hardness and strength with a satisfactory plasticity in the whole temperature range studied. The strength of this composite material in 2 or 4 times higher than that of known $\mathrm{Cu}-\mathrm{Al}_{2} \mathrm{O}_{3}$ and $\mathrm{Cu}-\mathrm{BeO}$ powder composites and cast copper super alloys.

The electrical conductivity of MDK composite materials by Cu-Zr-Y-Mo system ranges from $65 \%$ to $75 \%$ of that of copper, which is almost twice as much as that of all known Cu-Mo powder compositions. Their maximum magnitude of transferred current (up to $4000 \mathrm{~A}$ ) is 2.5 times higher than that of silver. MDK composite materials significantly surpass all existing electrical engineering materials in radiation resistance, thermal stability, and wear resistance. They exhibit high thermal conductivity, do not maintain the arc, and are more corrosion-resistant and durable than silver [10].

Additional alloying of the copper matrix with yttrium and zirconium allowed us to modify greatly the composition of the oxide film appearing in operation when the condensed material is in an oxidizing medium. Unlike Mo-Cu powder composites where the oxide films consist of $\mathrm{CuO} \times \mathrm{MoO}_{3}$ and $3 \mathrm{CuO} \times 2 \mathrm{MoO}_{3}$ compounds, the films of condensed materials are formed on the basis of complex spinels, such $\mathrm{CuMoY}_{2} \mathrm{O}_{7}$ and $\mathrm{CuMoZrY}_{2} \mathrm{O}_{9}$. In such oxide films no polymorphic transformations occur and they are distinguished by a high electrical conductivity and adhesion to the base material.

Electrical contacts made of $\mathrm{Cu}-\mathrm{Zr}-\mathrm{Y}$-Mo microlayer CMs exhibit high thermal and electrical corrosion resistance. They are unweldable and meet all increasing demands for the reliability and service life of high-current switchgear (Figure 4(a)). 


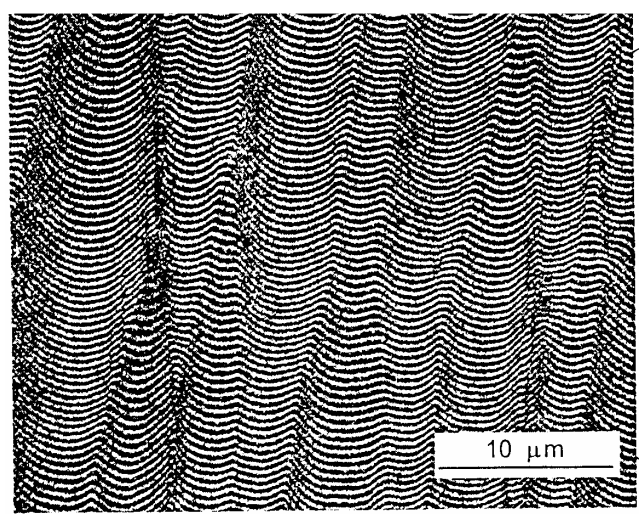

(a)

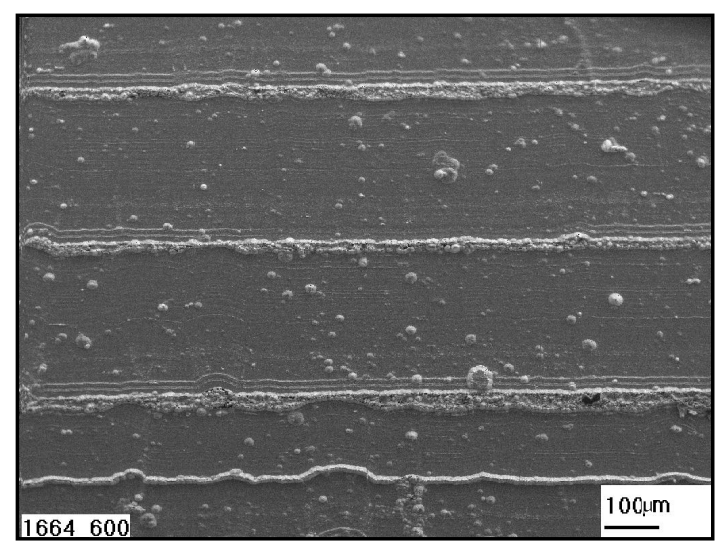

(c)

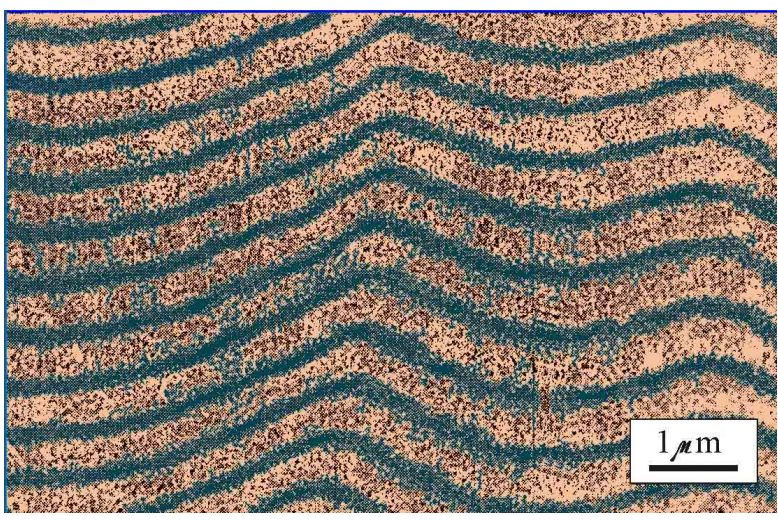

(b)

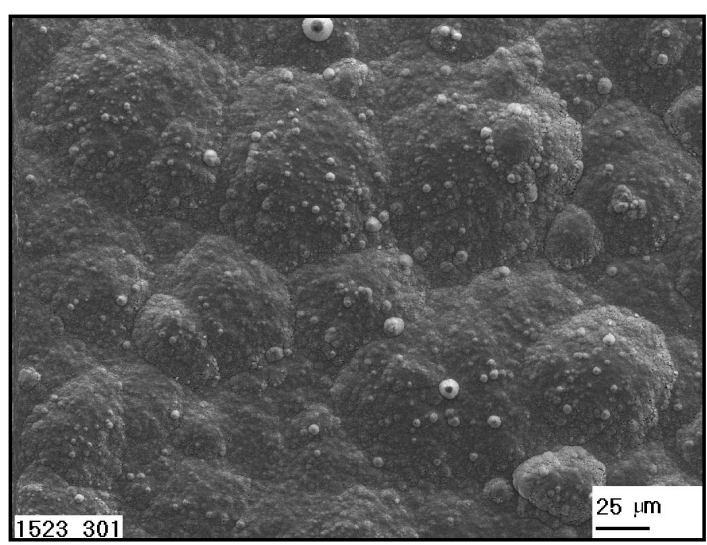

(d)

Figure 3. Microstructure of Cu-Zr-Y-Mo (a, b) and Cu-Zr-Y-C (c), (d) composite materials: (a)-(c): micro-layer structure of the composites, observed after ion etching; d: composite surface microstructure (without ion etching). Scanning electron microscopy.

Table 1. Standard values of physical, mechanical, and performance characteristics of mdk materials.

\begin{tabular}{cccccc} 
Material type & $\begin{array}{c}\text { Molybdenum content, } \\
\text { wt.\% }\end{array}$ & $\begin{array}{c}\text { Density, } \\
\mathrm{g} / \mathrm{cm}^{2}\end{array}$ & $\begin{array}{c}\text { Vickers hardness, } \\
\text { MPa }\end{array}$ & $\begin{array}{c}\text { Electrical resistivity, } \\
\text { Ohm } \cdot \mathrm{mm}^{2} / \mathrm{m}\end{array}$ & $\begin{array}{c}\text { Rated current of contacts, } \\
\text { A }\end{array}$ \\
\hline MDK-1 & $2.5-5.0$ & $8.98-9.00$ & $1000-1500$ & $0.021-0.022$ & up to 10 \\
MDK-2 & $5.1-8.0$ & $9.00-9.05$ & $1500-1650$ & $0.022-0.024$ & up to 100 \\
MDK-3 & $8.1-12.0$ & $9.05-9.10$ & $1650-1750$ & $0.024-0.028$ & up to 100 \\
\hline
\end{tabular}

Table 2. Hardness, strength, and plasticity of MDK-3 composite material in the temperature range from 290 to $1070 \mathrm{~K}$.

\begin{tabular}{|c|c|c|c|c|c|}
\hline$T, \mathrm{~K}$ & $H V, \mathrm{MPa}$ & $R_{\mathrm{m}}, \mathrm{MPa}$ & $R_{\mathrm{p} 0,2}, \mathrm{MPa}$ & $A, \%$ & $Z, \%$ \\
\hline 290 & 1800 & 645 & 595 & 8.7 & 37.6 \\
\hline 370 & 1350 & 570 & 535 & 8.8 & 18.3 \\
\hline 470 & 1065 & 475 & 440 & 12.4 & 33.1 \\
\hline 570 & 775 & 350 & 330 & 1.8 & 7.0 \\
\hline 670 & 575 & 290 & 265 & 7.9 & 13.5 \\
\hline 770 & 414 & 205 & 185 & 8.8 & 12.8 \\
\hline 870 & 305 & 140 & 130 & 13.1 & 9.1 \\
\hline 970 & 215 & 82 & 73 & 17.1 & 16.6 \\
\hline 1070 & 150 & 45 & 39 & 21.7 & 33.7 \\
\hline
\end{tabular}


Nowadays composites based on copper and chromium are the most effective electrical contact materials for interrupter contacts in vacuum circuit breakers. Experimental-industrial layered composite materials by $\mathrm{Cu}-\mathrm{Zr}-$ Y-Cr system with chromium content of 30.0 - 40.0 mas.\% are produced in Ukraine by the Gekont (Eltechmash) Science \& Technology Company. Electrical resistivity of this composites does not exceed $2.5 \times 10^{-2}$ $\mathrm{Ohm} \cdot \mathrm{mm}^{2} / \mathrm{m}$. Mechanical characteristics of the Cu-Zr-Y-Cr composite material with average chromium content of $40.0 \pm 0.5$ mas.\% in the temperature range from 290 to $1070 \mathrm{~K}$ are given in Table 3 .

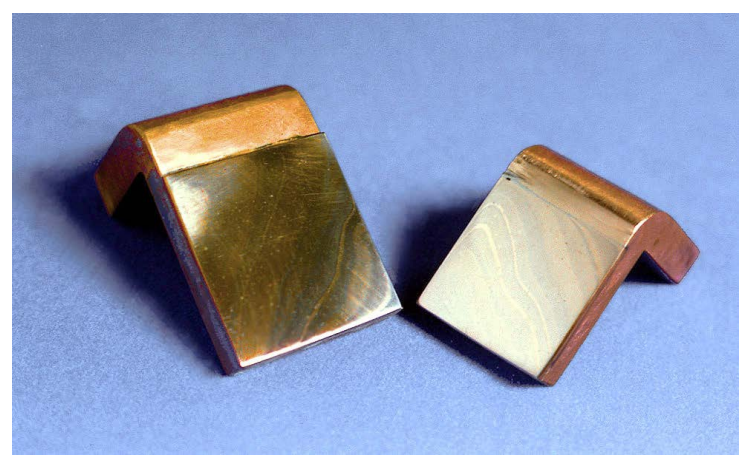

(a)

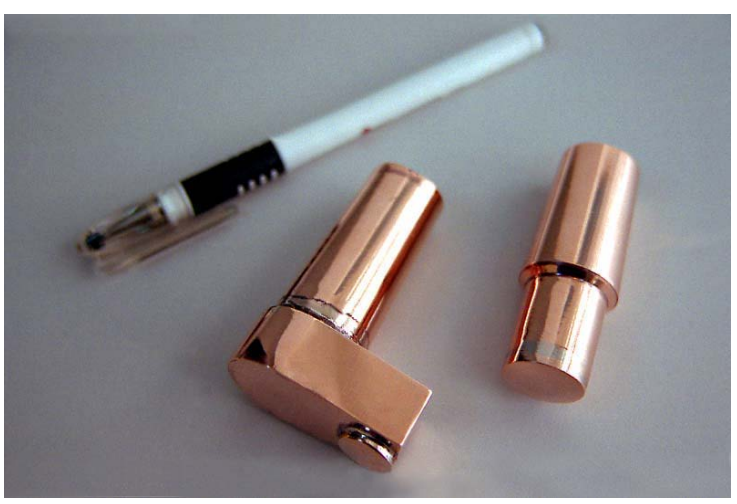

(c)

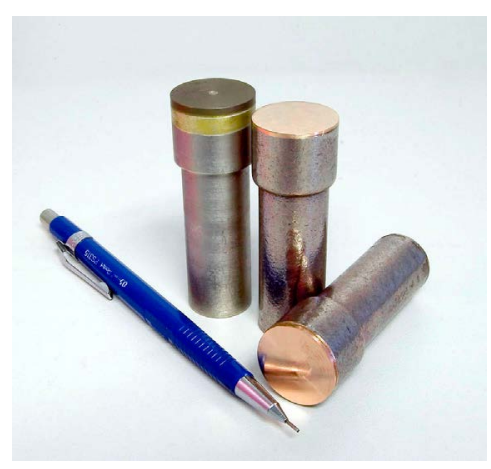

(b)

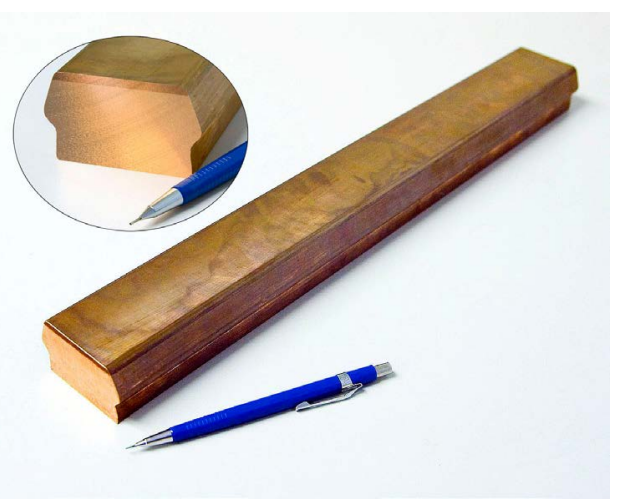

(d)

Figure 4. Production samples of electrical contacts and electrodes made on basis of Cu-Zr-Y-Mo (a), Cu-Zr-Y-Cr (b), $\mathrm{Cu}-\mathrm{Zr}-\mathrm{Y}-\mathrm{W}$ (c), and Cu-Zr-Y-C (d) microlayer CMs: (a) gamma-type interrupting electrical contacts for high-current switchgears; (b) cylindrical interrupting contacts for vacuum circuit breakers; (c) electrodes for contact welding; (d) sliding contact for current-collecting devices.

Table 3. Hardness, strength, and plasticity of Cu-Zr-Y-Cr composite material with average chromium content of $40.0 \pm 0.5$ mas.\% in the temperature range from 290 to $1070 \mathrm{~K}$.

\begin{tabular}{|c|c|c|c|c|c|}
\hline$T, \mathrm{~K}$ & $H V, \mathrm{MPa}$ & $R_{\mathrm{m}}, \mathrm{MPa}$ & $R_{\mathrm{p} 0,2}, \mathrm{MPa}$ & $A, \%$ & $Z, \%$ \\
\hline 290 & 1690 & 362 & 257 & 10.5 & 28.8 \\
\hline 370 & 1435 & 310 & 220 & 27.3 & 55.5 \\
\hline 470 & 1230 & 220 & 160 & 38.6 & 64.5 \\
\hline 570 & 995 & 157 & 116 & 45.0 & 65.0 \\
\hline 670 & 790 & 125 & 93 & 48.5 & 56.0 \\
\hline 770 & 620 & 88 & 70 & 39.0 & 45.4 \\
\hline 870 & 435 & 62 & 53 & 25.7 & 38.3 \\
\hline 970 & 245 & 38 & 35 & 23.3 & 37.5 \\
\hline 1070 & 138 & 21 & 19 & 22.0 & 35.0 \\
\hline
\end{tabular}


Electrical interrupting contacts for vacuum circuit breakers made of Cu-Zr-Y-Cr microlayer composite materials exhibit high thermal and electrical corrosion resistance. They are unweldable and meet all increasing demands for the reliability and service life of vacuum circuit breakers (Figure 4(b)).

Owing to the highest hardness and strength together with satisfactory plasticity at higher temperatures (Table 4) condensed composites of Cu-Zr-Y-W system are very promising as materials for operating floors of electrodes in contact welding (Figure 4(c)). The electrical resistance of these composites depends on tungsten content and does not exceed $3.05 \times 10^{-2} \mathrm{Ohm} \cdot \mathrm{mm}^{2} / \mathrm{m}$ (for CMs with 25 mas.\% W).

Condensed layered CMs of Cu-Zr-Y-C system with high tribotechnical characteristics are used for manufacturing sliding contacts for current-collecting devices of electric transport (Figure 4(d)). The coefficient of kinetic friction of $\mathrm{Cu}-\mathrm{Zr}-\mathrm{Y}-\mathrm{C}$ composites with 4.0 - 7.0 vol.\% C together with copper contact wire is 3 - 4 fold lower than that of the tough-pitch copper. Mechanical characteristics of the $\mathrm{Cu}-\mathrm{Zr}-\mathrm{Y}-\mathrm{C}$ composite material with average carbon content of $5.0 \pm 0.2 \mathrm{vol} . \%$ in the temperature range from 290 to $870 \mathrm{~K}$ are given in Table 5 .

\section{Summary}

1) A manufacturing technology for obtaining condensed microlayered composite materials of the Cu-ZrY-Mo, Cu-Zr-Y-Cr, Cu-Zr-Y-W, and Cu-Zr-Y-C systems by means of high-speed electron-beam evaporationcondensation is developed. The CMs components are evaporated from separate crucibles and then precipitated on a rotating steel substrate. Condensed composites with a thickness of 3 - $5 \mathrm{~mm}$ and regulated content of refractory components, which are very promising as materials for electrical contacts and electrodes, are obtained industrially.

Table 4. Hardness, strength, and plasticity of Cu-Zr-Y-W composite material with average tungsten content of $25.0 \pm 0.5$ mas.\% in the temperature range from 290 to $1070 \mathrm{~K}$.

\begin{tabular}{cccccc}
\hline$T, \mathrm{~K}$ & $H V, \mathrm{MPa}$ & $R_{\mathrm{m}}, \mathrm{MPa}$ & $R_{\mathrm{p} 0,2}, \mathrm{MPa}$ & $A, \%$ & $Z, \%$ \\
\hline 290 & 1950 & 680 & 650 & 13.5 & 27.0 \\
370 & 1660 & 600 & 565 & 14.8 & 34.3 \\
470 & 1420 & 510 & 465 & 16.4 & 36.1 \\
570 & 1145 & 375 & 350 & 17.8 & 37.5 \\
670 & 910 & 285 & 19.5 & 41.5 \\
770 & 720 & 185 & 185 & 20.4 & 40.8 \\
870 & 505 & 132 & 170 & 17.5 & 35.5 \\
970 & 360 & 75 & 65 & 20.7 & 34.5 \\
\hline
\end{tabular}

Table 5. Hardness, strength, and plasticity of Cu-Zr-Y-C composite material with average carbon content of $5.0 \pm 0.2$ vol.\% in the temperature range from 290 to $870 \mathrm{~K}$.

\begin{tabular}{|c|c|c|c|c|c|}
\hline$T, \mathrm{~K}$ & $H V, \mathrm{MPa}$ & $R_{\mathrm{m}}, \mathrm{MPa}$ & $R_{\mathrm{p} 0,2}, \mathrm{MPa}$ & $A, \%$ & $Z, \%$ \\
\hline 290 & 951 & 257 & 225 & 8.5 & 28.2 \\
\hline 370 & 724 & 213 & 186 & 6.7 & 24.6 \\
\hline 470 & 571 & 167 & 153 & 4.6 & 22.0 \\
\hline 570 & 381 & 127 & 117 & 4.5 & 20.2 \\
\hline 670 & 290 & 104 & 96 & 6.0 & 18.3 \\
\hline 770 & 177 & 65 & 59 & 6.6 & 17.4 \\
\hline 870 & 127 & 37 & 34 & 8.2 & 17.0 \\
\hline
\end{tabular}


2) Structure, electrical conductivity, hardness, tribotechnical and mechanical properties in tension of the microlayer CMs for electrical contacts and electrodes obtained by means of high-speed electron-beam evaporation-condensation were investigated at ambient and elevated temperatures.

3) The practical use of condensed CMs as materials for electrical applications will be based on a preliminary study of the operating conditions of the electrical contact or electrode, choice of chemical composition for a future combined product, and a detailed study of its production technology, which is determined by the required functional properties of the electrical switching devices.

4) Many years of series production and practical use of condensed microlayered CMs for electric contacts at Gekont Science \& Technology Company in Ukraine gave grounds to believe that the offered materials would be promising enough for wide commercial applications.

\section{Acknowledgements}

Authors express their thanks to president of Gekont Science \& Technology Company professor N.I. Grechanyuk and professor of Frantsevich Institute for Problems of Materials Science of National Academy of Sciences of Ukraine R.V. Minakova for the provided composite materials and help rendered during metallographic and electrophysical investigations.

\section{References}

[1] Gnesin, G.G. (1981) Sintered Materials for Electrical and Electronic Applications. Handbook, Metallurgy, Moscow.

[2] Rakhovsky, V.I., Levchenko, G.V. and Teodorovich, O.K. (1966) Interrupting Contacts of Electric Appliances, Energy. Leningrad, Moscow.

[3] Janković Ilić, D., Fiscina, J., González-Oliver, C.J.R., Ilić, N. and Mücklich, F. (2008) Electrical and Elastic Properties of Cu-W Graded Material Produced by Vibro Compaction. Journal of Materials Science, 43, 6777-6783. http://dx.doi.org/10.1007/s10853-008-2941-2

[4] Li, Y., Qu, X., Zheng, Z., Lei, C., Zou, Z. and Yu, S. (2003) Properties of W-Cu Composite Powder Produced by a Thermo-Mechanical Method. International Journal of Refractory Metals and Hard Materials, 21, 259-264. http://dx.doi.org/10.1016/j.ijrmhm.2003.08.001

[5] Chen, G., Jiang, L., Wu, G., Zhu, D. and Xiu, Z. (2007) Fabrication and Characterization of High Dense Mo-Cu Composites for Electronic Packaging Applications. Transactions of Nonferrous Metals Society of China, 17, 580-583.

[6] Müller, R. (1988) Arc-Melted Cu-Cr Alloy as Contact Materials for Vacuum Interrupters, Siemens Forsch. Entwicklungsber, 17-33, 105-111.

[7] Kim, M., Doh, J., Park, J. and Jung, J. (2001) Microstructural Evolution in the Cr-Cu Electric Contact Alloys during Liquid Phase Sintering. Proceedings of the 15th International Plansee Seminar, Plansee Holding AG, Reutte, 1, 29-43.

[8] Grechanyuk, N., Mamuzić, I. and Shpak, P. (2002) Modern Electron-Beam Technologies of Melting and Evaporation of Materials in Vacuum, Used by Gekont Company, Ukraine. Metalurgija, 41, 125-128.

[9] Grechanyuk, N.I., Osokin, V.A., Grechanyuk, I.N. and Minakova, R.V. (2005) Vapour-Phase Condensed Materials Based on Copper and Tungsten for Electrical Contacts. Structure, Properties, Technology. Current Situation and Prospects for Using Electron Beam Physical Vapour Deposition Technique to Obtain Materials for Electrical Contacts, First Announcement. Modern Electrometallurgy, 2, 28-35.

[10] Grechanyuk, N.I., Osokin, V.A., Grechanyuk, I.N. and Minakova, R.V. (2006) Basics of Electron Beam Physical Vapour Deposition Technique Used to Obtain Materials for Electrical Contacts. Structure and Properties of Electrical Contacts, Second Announcement. Modern Electrometallurgy, 2, 9-19.

[11] Bukhanovskii, V.V., Rudnitsky, N.P. and Mamuzić, I. (2006) Effect of Chemical Composition and Heat Treatment on Mechanical Characteristics of Microlayer Composite Materials of the Cu-Zr-Y-Mo System in Wide Temperature Range. Metals Science and Heat Treatment, 48, 113-117. http://dx.doi.org/10.1007/s11041-006-0053-7

[12] Grechanyuk, N.I., Mamuzić, I. and Bukhanovsky, V.V. (2007) Production Technology and Physical, Mechanical, and Performance Characteristics of Cu-Zr-Y-Mo Finely-Dispersed Microlayer Composite Materials. Metalurgija, 46, 9396.

[13] Bukhanovskii, V.V., Mamuzić, I. and Rudnitsky, N.P. (2008) The Effect of Temperature on Mechanical Characteristics of Copper-Carbonic Composite. Kovove Materialy (Metallic Materials), 46, 33-37.

[14] Grechanyuk, N.I., Mamuzić, I. and Minakova, R.V. (2008) Peculiarities of the Structure, ITS Deformation and Destruction of Condensed Cu-Mo-Zr-Y Composite Material of Commercial Purity. Metalurgija, 47, 99-102.

[15] Bukhanovskii, V.V., Rudnitsky, N.P. and Mamuzić, I. (2009) The Effect of Temperature on Mechanical Characteris- 
tics of Copper-Chromium Composite. Materials Science and Technology, 25, 1057-1061. http://dx.doi.org/10.1179/174328408X365829

[16] Bukhanovskii, V.V., Rudnitsky, N.P., Mamuzić, I., Minakova, R.V. and Grechanyuk, N.I. (2009) Effect of Composition and Process Factors on the Structure, Mechanical Properties, and Fracture Behavior of a Composite Material of Copper-Chromium System. Metals Science and Heat Treatment, 51, 388-393. http://dx.doi.org/10.1007/s11041-009-9168-y

[17] Bukhanovskii, V.V., Rudnitsky, N.P., Kharchenko, V.V. and Mamuzić, I. (2010) Relationship between Hardness and Strength Characteristics of Cu-Cr Microlayer Composite Material at Elevated Temperatures. Strength of Materials, 42, 187-196. http://dx.doi.org/10.1007/s11223-010-9206-4

[18] Kluev, V.V. (1982) Test Equipment. Handbook, Mashinostroenie, Moscow.

[19] Metallic Materials (1998) Tensile Testing at Ambient Temperature.

[20] Metallic materials (1999) Tensile Testing at Elevated Temperature.

[21] Aleksyuk, M.M., Borisenko, V.A. and Krashchenko, V.P. (1980) Mechanical Tests at High Temperatures. Naukova Dumka, Kiev.

[22] Borisenko, V.A. (1984) Hardness and Strength of Refractory Materials at High Temperatures. Naukova Dumka, Kiev.

[23] Borisenko, V.A. and Oksametna, O.B. (1995) DSTU 2434-94 Method of Determining High-Temperature Hardness by Pyramidal and Bicylindrical Indentation. Kiev. 